\title{
Neuroprotective Properties of Nigella sativa (L.) Seeds Extract in Sprague Dawley Rats models
}

\section{Zahir Uddin Babar ${ }^{1}$, Abul Kalam Azad ${ }^{1}$, Wan Mohd Azizi Wan Sulaiman ${ }^{1}$, $J$ alal Uddin ${ }^{2}$ and Zubair Khalid Labu ${ }^{2}$}

\author{
${ }^{1}$ Department of Basic Medical Science, Faculty of Pharmacy, International Islamic University Malaysia, 25200 \\ Kuantan, Pahang, Malaysia \\ ${ }^{2}$ Department of Pharmacy, World University of Bangladesh, 151/8, Geen Road, Dhaka-1205, Bangladesh
}

(Received: 22 November, 2017; Accepted: 15 May, 2018; Published (web): 10 June, 2018)

\begin{abstract}
Neuroinflammation has been closely linked to neurodegeneration that leads to dysfunction of memory and learning where glial fibrillary acidic protein (GFAP) plays important role positively within hippocampus. In experimental neurodegeneration achieved by two-vessel occlusion (2VO) intervention, Nigella sativa (L.) seeds extract $(50 \mathrm{mg} / \mathrm{kg} /$ day orally) has shown to have anti-neuroinflammatory and antioxidant properties. The brain hippocampal tissues were humanely collected at the end of 10th treatment week and preserved in Allprotect ${ }^{\mathrm{TM}}$ reagent at $-80^{\circ} \mathrm{C}$. Total RNA was extracted and purified by phenol/chloroform method using kits and reverse transcribed into cDNA and relatively quantified as per $\Delta \Delta \mathrm{Cq}$. The NSSE treatment showed significantly $(\mathrm{p}<0.001)$ different relative GFAP mRNA expression in the treated group as compared to that of untreated $2 \mathrm{VO}$ whilst it was insignificantly ( $>0.5$ ) different to that of healthy control (HC). Prolonged or daily treatment with NSSE (Nigella sativa (L.) seeds extract) may provide moderate anti-neuroprotective activity within hippocampus.
\end{abstract}

Key words: Nigella sativa, neuroinflammation, two-vessel occlusion, glial fibrillary acidic protein, hippocampus, reverse transcription quantitative PCR (RT-qPCR).

\section{INTRODUCTION}

Neuroinflammation occurs in almost all types of neurodegenerative diseases varying to unique pathology and symptoms having specific triggers of neuronal damage. ${ }^{1}$ The glial fibrillary acidic protein (GFAP) controls the up or down regulation of astrocytes (astroglia collectively) is closely linked to neuroinflammation and considered as a relevant biomarker for astrogliosis (also known as astrocytic hypertrophy) after any peripheral nerve injury and also associated to Alzheimer's disease. ${ }^{2,3}$ Anatomically, it is the major constituent of glial intermediate filaments (IF) protein found mainly in differentiated fibrous and protoplasmic astrocytes of the brain and spinal cord of the central nervous system. GFAP becomes activated in response to

Correspondence to: Zubair Khalid Labu

E-mail: zubair.labu@yahoo.com Tel.:+ 8801558388956

Dhaka Univ. J. Pharm. Sci. 17(1): 113-121, 2018 (June) immunologic (infiltration of leucocytes from residential cells) challenges or brain injuries that cause restriction of blood flow and deprivation of oxygen supply to hippocampus. ${ }^{4,5}$ It has been reported that activated GFAP (i.e., hypertrophic astrocytes or astrogliosis) forms glial scars that hinder axonal regeneration while there is a clear relationship between astroglia and microtubule associated protein (MAP) or microglia in both resting and activated conditions. ${ }^{6,7}$ Microtubule associated protein 2 (MAP2) has been considered as important bio-marker linked to neuroprotection in response to neuronal damage or any kind of central nervous system injury. ${ }^{8-10}$ MAP2 has been found to be downregulated in experimental neurodegenera-tion of twovessel occluded (2VO) rats. ${ }^{11}$ The neurotoxic activation of MAP2 or microglia in response to neuronal injury is commonly known as reactive microgliosis. Microglia consistently produces reactive oxygen species (ROS) when activated by 
multiple pro-inflammatory triggers, endogenous protein toxins ( $\beta$-amyloid peptide, $\alpha$-synuclein) and neuronal injury. It has been reported that MAP2 mRNA expression plays a crucial role in neuronal plasticity and synaptic intact ${ }^{12}$, while GFAP mRNA in neuroinflammation. It was also believed that these two proteins are sensitive to experimental neurodegeneration attained by (2VO), a surgical method that needs ligature of both left and right carotid arteries permanently. ${ }^{13-15}$ This procedure has been widely used and recognized for its effective induction of neurodegeneration in animal models. ${ }^{16,17}$ The present study was designed to explore the role of GFAP in $N$. sativa mediated neuroinflammation.

\section{MATERIALS AND METHODS}

Animals and treatments. 18 Male healthy adult SD (Sprague Dawley) rats (250-350 gm) were randomly divided into three groups $(\mathrm{n}=6)$, Healthy Control (HC), 2VO untreated (2VO) and $2 \mathrm{VO}+$ NSSE treated (NSSE) after one week of acclimatization. The (NSSE) group was pre-treated $(50 \mathrm{mg} / \mathrm{kg} /$ day) for 10 successive days and it was continued until all the animals were sacrificed at the end of 10th postoperative week. The animals had free access to standard laboratory food and water adlibitum, and two animals were housed in each cage under (12 hr) light-dark cycle. The care for laboratory animals was taken as per guidelines of the Guide for the Care and Use of Laboratory Animals (National Institute of Health Publication) as well as the guidelines and recommendations of IIUM ethical committee and Malaysian National Animal Welfare Foundation.

Plant material and chemicals. About $1,020 \mathrm{~g}$ of commercially available powdered Nigella sativa (L.) seeds was purchased in the month of January, 2016 from a local Mini-supermarket called 'Zam Zam' located in Kuantan of Pahang, Malaysia.

Extraction process. About $1 \mathrm{~kg}$ of powdered seeds was soaked in $2.5 \mathrm{~L}(1: 2.5 \mathrm{w} / \mathrm{v})$ of $98 \%$ methanol for 72 hours at room temperature, $25 \pm 1{ }^{\circ} \mathrm{C}$. After 72 hours, the dark brown colour medium was filtered using a filter funnel and hand-held mechanical vacuum pump. The filtrate was dried using rotary evaporator (IKA ${ }^{\circledR} \mathrm{RV} 10$ Basic) at 120 $160 \mathrm{rpm}$, low pressure and temperature, $40^{\circ} \mathrm{C}$. The recovered solvent was reused for three successive refluxes carried after every $24 \mathrm{hr}$ of additional soaking. Initially, the oily concentrate weighing $292.27 \mathrm{~g}$ or $331.42 \mathrm{~mL}$ dark brown in colour was kept at $50^{\circ} \mathrm{C}$ for 8 days continuously without a disturbance for further drying in the laboratory dryer (FDD-720, Tech-Lab Scientific Sdn Bhd). After confirming that it was solvent-free and the weight was recorded as of $278.53 \mathrm{~g}$ or $315.81 \mathrm{~mL}$ (i.e., $4.7 \%$ reduction from initial weight) before it was transferred to the CFC-free glass door chiller (CHILL-1050) at $4^{\circ} \mathrm{C}$ to keep the apparent oily extract. After 8 days of chilling, it was then thawed at room temperature for about 20 minutes before it was decanted to obtain a significant amount of $N$. sativa seeds oil (NSO) $208.82 \mathrm{~g}$ or $20.9 \% \mathrm{w} / \mathrm{w}$. This method of extraction has been adopted with slight modifications. $^{18}$

The extract was dissolved in olive oil before it was given using a gavage (cannula) at a daily dose of $50 \mathrm{mg} / \mathrm{kg}$ of body weight having a concentration of 1 $\mathrm{mg} / 0.02 \mathrm{ml}$ (extract/vehicle) $(\mathrm{n}=6)$ with an average weight of $300 \mathrm{~g}$. The pre-treatment was conducted with the same dose of the extract for 10 successive days before $2 \mathrm{VO}$ surgery was conducted.

Two-vessel occlusion (2VO) surgery. A small ventral mid-line incision of $2 \mathrm{~cm}$ in length was made just above the sternal bone of the neck area to expose both the left and right common carotid arteries under aseptic conditions after pre-anaesthetic preparation of atropine sulphate $(0.1 \mathrm{mg} / \mathrm{kg})$ was given intramuscularly to prevent respiratory distress. As general anaesthesia, a combination of ketamine and xylazine injection of $(90 \mathrm{mg} / \mathrm{kg}$ and $0.1 \mathrm{mg} / \mathrm{kg}$ ) respectively was given intraperitoneally as earlier mentioned. Arteries were isolated with gentle tweezing of neck muscles from each of the carotid sheath and vagus nerve for proper identification before making ligatures using silk suture (5-0 size) just below the carotid bifurcation into internal and external carotid arteries. ${ }^{19}$ With the exception of 
occlusion of carotid arteries, surgical procedure in healthy control animals was as similar as those of $2 \mathrm{VO}$. After surgery, the rats were closely monitored at their respective cages for the first 24 hours during post-operative recovery while the temperature was maintained at $37^{\circ} \mathrm{C}$ with a heating lamp to avoid from incidental hypothermia until complete recovery from the general anaesthesia. Following recovery, a single intraperitoneal injection of buprenorphine (0.05 $\mathrm{mg} / \mathrm{kg}$ ) was given to reduce neck muscles pain efficiently as it was not commenced to provide water immediately.

Collection and storage of hippocampal tissues. All the animals were humanely euthanized using over-dosed diethyl ether inhalation at the end of the 10 th postoperative week. The hippocampal tissue from each brain sample was identified, dissected to collect quickly on ice-cold stainless steel tray with ice-cold surgical forceps to prevent physicochemical degradation of the tissues as it is reported that lipid tissues are highly susceptible to surrounding temperature. The room temperature and aseptic conditions were maintained for the whole process. The samples were then immediately stored in Allprotect ${ }^{\mathrm{TM}}$ tissue reagent (Qiagen, Germany) at $20^{\circ} \mathrm{C}$ until further processing.

Total RNA extraction. Prior to tissue disruption and homogenization, the weight of all 18 individual hippocampal tissues were taken to quantify the starting material which was $26 \mathrm{mg}$ by average weight and the variation was less than $\pm 10 \%$. Total RNAs from hippocampal tissues were then extracted by QIAzol ${ }^{\circledR}$ Lysis reagent $\left(\begin{array}{llll}450 & - & 600 & \mu \mathrm{l}\end{array}\right)$ using TissueRuptor $^{\mathrm{TM}}$ attached with disposable probes according to manufacturer's protocol (RNeasy Lipid Tissue Mini Kit, Qiagen, Germany). The homogenate formed was kept on bench-top for $5-7 \mathrm{~min}$ at $18^{\circ} \mathrm{C}$ to disperse the foam before adding $200 \mu \mathrm{l}$ of chloroform followed by vortexing for $15 \mathrm{~s}$. The lysate was again kept for $3 \mathrm{~min}$ on the bench-top at room temperature. Then, it was subjected to centrifugation at $12,000 \mathrm{x}$ g for $15 \mathrm{~min}$ at $4^{\circ} \mathrm{C}$. The clear aqueous phase (i.e., the uppermost layer) of $600 \mu \mathrm{l}$ was transferred into a new collection tube $(2 \mathrm{ml})$ in which $600 \mu \mathrm{l}$ of $70 \%$ ethanol (supplied) was added and mixed thoroughly by pipetting up and down followed by vortexing for seconds. The sample $(700 \mu \mathrm{l})$ was transferred again into RNeasy Mini Spin column placed in a $2 \mathrm{ml}$ collection tube and centrifuged at $8,000 \times \mathrm{g}$ for $15 \mathrm{~s}$ at room temperature. After discarding the flowthrough, $700 \mu$ of buffer RW1 was added to the spin column and centrifuged at $8,000 \mathrm{x} g$ for $15 \mathrm{~s}$ at room temperature. Again, the flow-through was discarded before adding $500 \mu \mathrm{l}$ of buffer RPE to the spin column and centrifuged at $8000 \mathrm{x}$ g for $15 \mathrm{~s}$ at room temperature. The flow-through was discarded; again $500 \mu \mathrm{l}$ of buffer RPE was added to the column before centrifugation at $8,000 \times \mathrm{g}$ for $2 \mathrm{~min}$. The spin column was carefully removed from $2 \mathrm{ml}$ tube and placed it back to a new $1.5 \mathrm{ml}$ tube and added $30 \mu \mathrm{l}$ of RNase-free water directly to the column membrane and centrifuged at $8000 \mathrm{x}$ g for $1 \mathrm{~min}$ after which the spin column was removed and the pure total RNA sample was immediately labelled and stored at $-80^{\circ} \mathrm{C}$ for experimental use. In short, total ribonucleic acid (RNA) from 18 samples having an average weight of $26 \mathrm{mg}$ per tissue was extracted by acid guanidiumthiocyanate-phenol-chloroform method involving photophobic QIAzollysis reagent as described in RNeasy ${ }^{\circledR}$ Lipid Tissue Handbook (Qiagen, Germany).

RNA quality and integrity. As the sample degradation mainly depends on collection method, the storage and preservation of tissues, here, we preserved the samples with Allprotect ${ }^{\mathrm{TM}}$ tissue reagent (Qiagen, Germany) at $-30^{\circ} \mathrm{C}$ for less than six months when they were harvested. The purity and quality of RNA samples by ratio of OD260/280 $(\geq 1.8$ to 2.0) and quantity in $\mathrm{ng} / \mu \mathrm{l}$ were determined by UV/VIS spectrophotometric method. As the integrity of total RNA could not be traced by UV/VIS method of $260 \mathrm{~nm}$ (specific for nucleic acid) and $280 \mathrm{~nm}$ (specific for proteins), the high innovative lab-onchip technology of Experion ${ }^{\circledR}$ (Bio-Rad, USA). Here the Fleige and Pfaffl method ${ }^{20,21}$, was used for the investigation of ribosomal $28 \mathrm{~S} / 18 \mathrm{~S}$ ratio that plays an important role in determining the level of sample degradation. Only RNA samples with an A260 $\mathrm{nm} / \mathrm{A} 280 \mathrm{~nm}$ absorption ratio $\geq 1.8$ having RNA 


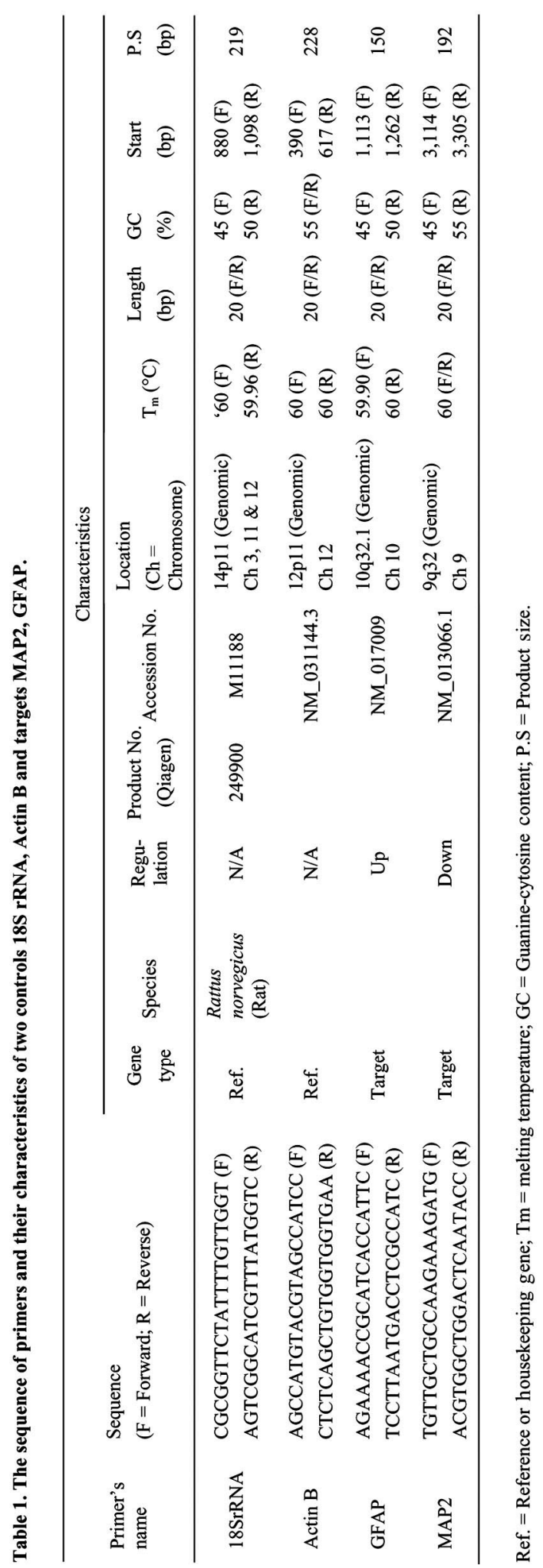


integrity (RQI) values between 7.5 and 10 were subjected to downstream RT-qPCR assay.

Reverse transcription (RT) and reverse transcript quantitative PCR (RT-qPCR) assay. After extraction, quantification and integrity of total RNA, $5 \mu 1(5 \mathrm{ng} / \mu \mathrm{l})$ of RNA was reversed by $4 \mu \mathrm{l}$ of $5 \mathrm{x}$ iScript ${ }^{\mathrm{TM}}$ Reverse Transcription Supermix for RTqPCR (Bio-Rad, Hercules, CA) that contains deoxynucleotide triphosphate (dNTP), oligo (dT), Moloney murine leukemia virus-reverse transcriptase MMLV-RT (RNaseH+), RNase inhibitor, random primer mix, gene-specific primer enhancer, buffer, $\mathrm{MgCl}_{2}$ and stabilizers where RNase-free water of $11 \mu 1$ made the final volume of $20 \mu 1$ in each reaction. The reaction conditions for RT by Mastercycler ${ }^{\circledR}$ Pro Thermal cycler (Eppendorf ${ }^{\circledR}$ ) were set according to manufacturer's protocol (iScript ${ }^{\mathrm{TM}}$, Bio-Rad). Quantitation of cDNA was determined by UV absorbance at $260 \mathrm{~nm}$ and $280 \mathrm{~nm}$ by BioPhotometer $^{\circledR}$ Plus with Hellma ${ }^{\circledR}$ Tray Cell (Eppendorf $^{\circledR}$ ). The standard curve analysis (Figure 1) was observed prior to RT-qPCR assay in six-log concentration by serial dilutions $(1: 10$ to 1:1,000,000) of randomly selected two RNA samples $(\mathrm{ng} / \mu \mathrm{l})$ from each group. The two-step reverse transcription quantitative PCR (RT-qPCR) was performed at pre-determined annealing temperature of $59^{\circ} \mathrm{C}$ by $(10 \mu \mathrm{l} /$ well $)$ of SsoFast $^{\mathrm{TM}}$ EvaGreen $^{\circledR}$ (SYBR Green I) based detection using 10x predesigned QuantiTect ${ }^{\mathrm{TM}}$ primers (Qiagen, Germany) ( $2 \mu \mathrm{l} /$ well) of two controls 18S rRNA, Actin B and targets MAP2, GFAP (Table 1) in technical replicates in a low-profile 96 -well plate of $20 \mu 1$ reaction that included $3 \mu \mathrm{l}$ of RNase-free water per well while NTC or No-RT was used RNase-free water alone. The melt curve analysis (Figure 2 and 3 ) at P-value 0.01 and regulation thresholds 4.00 were also respectively done by CFX®96 Real-Time System (Bio-Rad, Hercules, CA, USA). The intergroup comparison (Figure 4) was done based on the mean relative normalized gene expression $(\Delta \Delta \mathrm{Cq})$ levels where $\mathrm{Cq}$ is the threshold quantity at \pm 1 SEM as earlier mentioned method. The Minimum Information for publication of quantitative real-time
PCR experiments (MIQE) guidelines has been strictly maintained. ${ }^{22}$

Statistical analysis. Results expressed are the relative normalized gene expression ( $\Delta \Delta \mathrm{cq})$ as mean \pm sem. Statistical analysis of the data was done by independent, unpaired student t-test at $95 \%$ confidence interval (ci) using grappad® prism. The $\mathrm{p}$ values less than 0.05 were considered statistically significant.

\section{RESULTS AND DISCUSSION}

The relative normalized hippocampal GFAP and MAP2 mRNA expressions in 2VO rats treated with NSSE were expressed as mean \pm SEM (Figure 4) of technical replicates in $20 \mu \mathrm{l}$ reaction. The standard curve analysis (Figure 1 ) for each primer in a six-log concentration prepared by serial dilutions (102 to 107) from a mixture (5 $51 \times 2$ samples/group) of two randomly selected intact RNA samples representing each group was run together by conventional PCR method and observed at $59^{\circ} \mathrm{C}$. The melt-curve analysis (Figure 2 and 3) for each targeted gene was normalized and amwplified in parallel with the selected control genes (18s rRNA \& Actin B) while the inter-run calibrator (IRC) with known concentration of untreated control was maintained accordingly as prescribed below.

The core objective of the current study was to compare the relative gene expression $(\Delta \Delta \mathrm{Cq})$ of GFAP and MAP2 in NSSE treated 2VO male SD rats to that of $\mathrm{HC}$ and $2 \mathrm{VO}$ untreated as important biomarkers of neuroinflammation and neuroprotection on the progress of neurodegeneration which was experimentally achieved by $2 \mathrm{VO}$ surgery that uses permanent bilateral double ligature of common carotid arteries to restrict the cerebral blood flow and oxygen supply that resulted in ultimate brain ischemia and hypoxia. ${ }^{23,24}$ Previous studies on 2VOinduced neurodegeneration in vivo reported that GFAP was found to up-regulated indicating 'astrogliosis or hypertrophy' which has been considered as a late consequence of neuroinflammation due to chronic cerebral 
hypoperfusion taken place in hippocampus. whilst down-regulated MAP2 was found as the result of neuronal loss and/or damage in $2 \mathrm{VO}$ rats after chronic cerebral ischemia and hypoxia. ${ }^{25}$ Nevertheless, this is the first study on crude methanolic extract of the NSSE to report their antineuroinflammatory and neuroprotective effects explored via quantitative gene expression analysis of regulation of these two markers of neuroglial crises

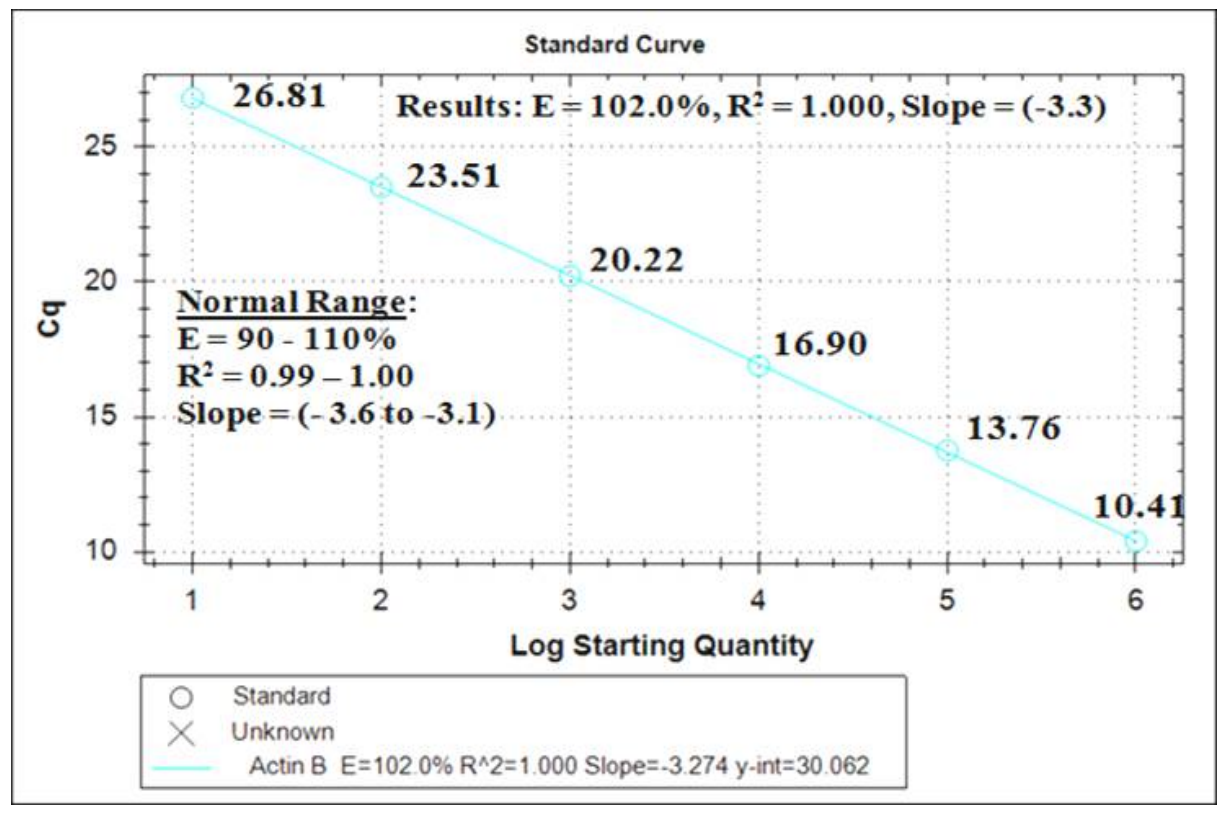

Figure 1. Standard curve analysis for one of the control genes (Actin B) in six-log concentration prepared by serial dilutions (1:10 to $1: 1,000,000)$ of two randomly selected pure RNA samples mixture of $5 \mu \mathrm{l}(5 \mathrm{ng} / \mu \mathrm{l}) \times 3$ groups. The resulted average cycle difference is 2.7 when $\mathrm{Cq}$ is the crossing point or quantification cycle run by $\mathrm{CFX} 96^{\circledR}$ Real-Time System.

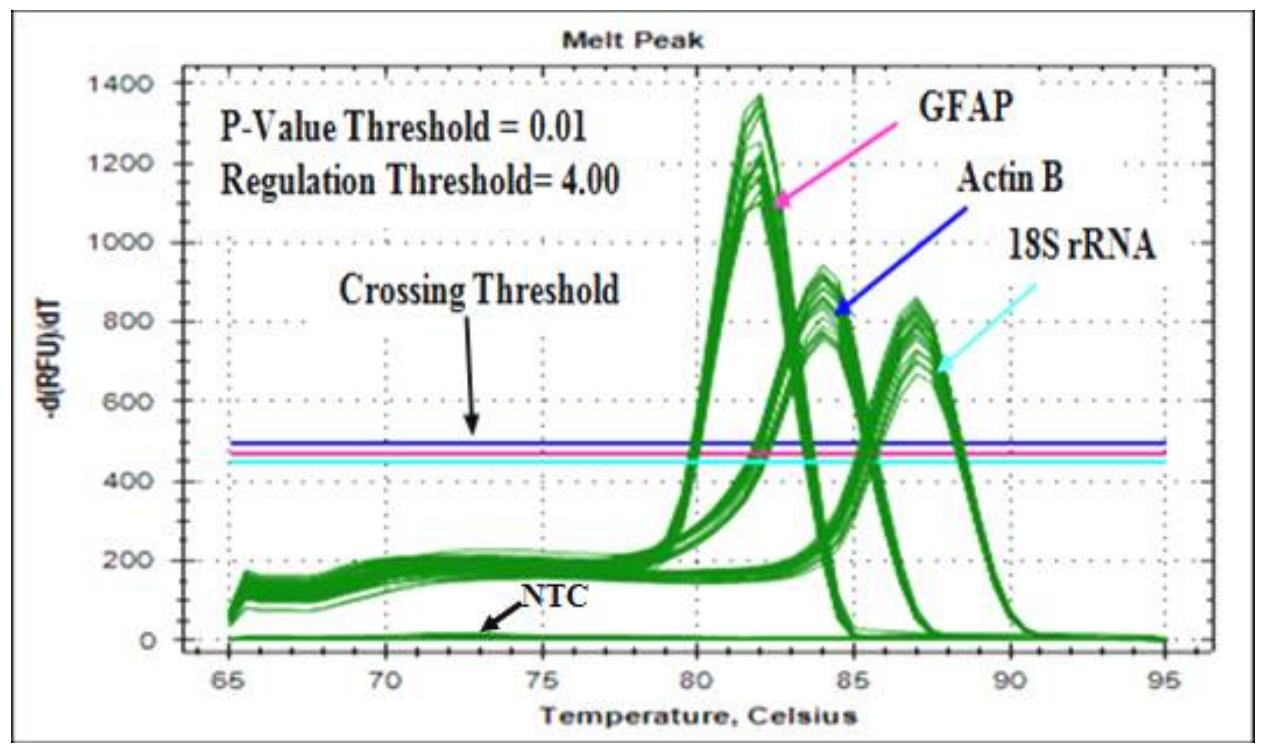

Figure 2. The melt curve analysis for targeted GFAP $m$ RNA expression of NSSE treatment in respect to the control genes (18S rRNA and Actin B) run by CFX $96^{\circledR}$ Real-Time System. 


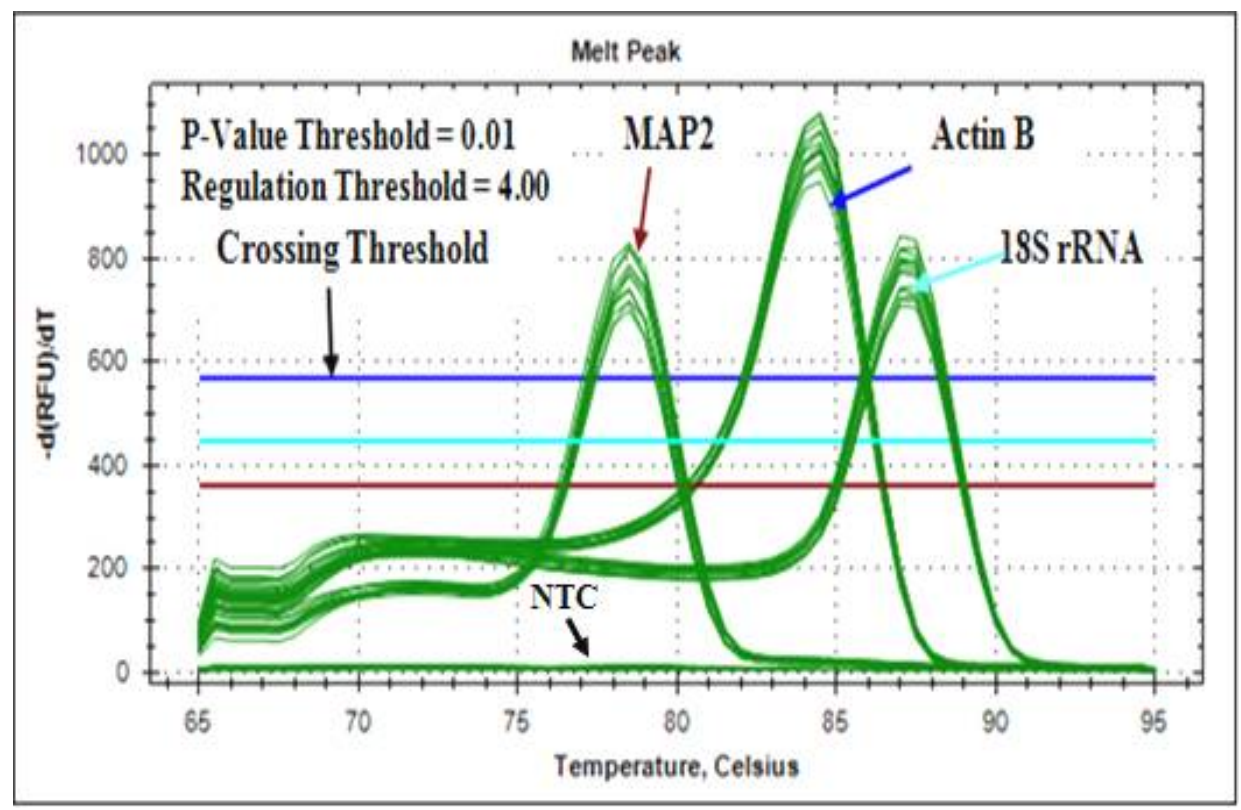

Figure 3. The melt curve analysis for targeted MAP2 $m$ RNA expression of NSSE treatment in respect to the control genes (18S rRNA and Actin B) run by $\mathrm{CFX} 96^{\circledR}$ Real-Time System.

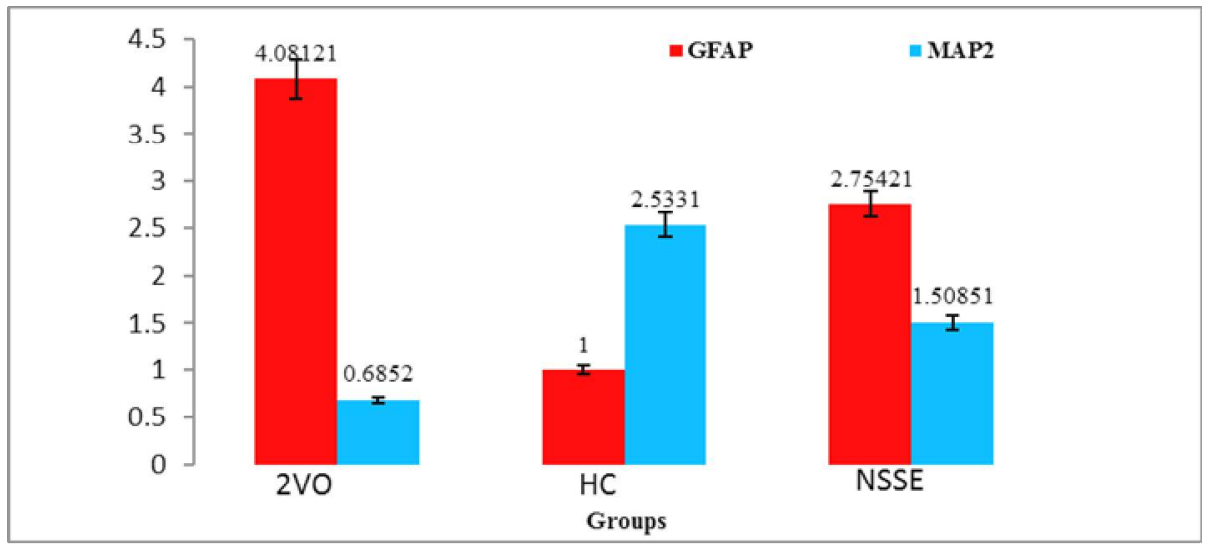

Figure 4. The gene expression analysis showing insignificantly different $(P>0.01)$ relative MAP2 $m$ RNA expressions $(\Delta \Delta \mathrm{Cq})$ of NSSE treated $(50 \mathrm{mg} / \mathrm{kg} /$ day $)$ group Vs. HC and $2 \mathrm{VO}$ while significantly different $(P<0.01)$ GFAP $m$ RNA expression of NSSE treated Vs. HC group run by CFX96 Real-Time System.

and neuronal wellbeing after chronic cerebral ischemia and hypoxia of 10 weeks duration. The results of the current study agreed with the previous reports made by Mani et al. $2013^{26}$ for anti-amnesic, anti-oxidant and anti-inflammatory activities of curry leaves respectively. The results of the current study (Figure 4) showed that there was significantly different $(\mathrm{p}<0.001)$ up-regulated GFAP mRNA expression in $2 \mathrm{VO}$ untreated group as compared to that of $\mathrm{HC}$ group indicating astrogliosis due to neuroglial activation even after 10 weeks of $2 \mathrm{VO}$ surgery while significantly different $(p<0.001)$ down-regulated MAP2 mRNA expression in $2 \mathrm{VO}$ as compared to that of $\mathrm{HC}$ group exhibiting neuronal damage due to apoptotic neurons. On the other hand, NSSE treatment showed significant difference $(\mathrm{p}<$ 0.05) of GFAP mRNA expression as compared to that of $2 \mathrm{VO}$ while it was not insignificantly different to that of $\mathrm{HC}$ group showing moderate antineuroinflammatory activity on chronic cerebral 
ischemia and hypoxia of $2 \mathrm{VO}$ treated rats. And the MAP2 mRNA expression in NSSE treated 2VO group was insignificantly $(\mathrm{P}=0.23)$ down-regulated as compared to that of $2 \mathrm{VO}$ whilst it was significantly less $(\mathrm{P}<0.001)$ than that of $\mathrm{HC}$ group.

\section{CONCLUSIONS}

By relative normalized gene expression $(\Delta \Delta \mathrm{Cq})$ analysis of the two selected markers (GFAP \& MAP2) of neuroglial crises and wellbeing of the brain hippocampal tissues studied (Figure 4), it could be concluded that NSSE extract of methanol treated as $50 \mathrm{mg} / \mathrm{kg} /$ day b.w for 10 weeks in $2 \mathrm{VO}$ rats, exhibited moderate anti-neuroinflammatory activity while it could have potential neuroprotective activity in experimental neurodegeneration.Further studies could be recommended using different solvent and extraction protocols.

\section{REFERENCES}

1. Block, M. L., Zecca, L. and Hong, J.S. 2007. Microgliamediated neurotoxicity: uncovering the molecular mechanisms. Nat. Rev. Neuro. 8, 57-69.

2. Garrison, C., Dougherty, P., Kajander, K. and Carlton, S. 1991. Staining of glial fibrillary acidic protein (GFAP) in lumbar spinal cord increases following a sciatic nerve constriction injury. Brain Res. 565, 1-7.

3. Hauss-Wegrzyniak, B., Dobrzanski, P., Stoehr, J. D. and Wenk, G. L. 1998. Chronic neuroinflammation in rats reproduces components of the neurobiology of Alzheimer's disease. Brain Res. 780, 294-303.

4. Pekny, M., Porritt, M., de Pablo, Y., Pekna, M. and Wilhelmsson, U. 2013. Reactive astrocytes, astrocyte intermediate filament proteins, and their role in the disease pathogenesis The Cytoskeleton pp. 299-319: Springer.

5. Aloisi, F. 1999. The role of microglia and astrocytes in CNS immune surveilance and immunopathology. Adv. Exp. Med. Biol. 468, 123-133.

6. Tacconi, M. T. 1998. Neuronal death: is there a role for astrocytes? Neurochem. Res. 23, 759-765.

7. Kahn, M.A., Speight, G.J. and de Vellis, J. 1995. CNTF regulaation of astrogliosis and the activation of microglia in the developing rat central nervous system. Brain Res. 685, 55-67.

8. Rezaie, P., Trillo-Pazos, G., Greenwood, J., Everall, I.P. and Male, D.K. 2002. Motility and ramification of human fetal microglia in culture: an investigation using time-lapse video microscopy and image analysis. Exp. Cell Res. 274, 68-82.
9. Harukuni, I. and Bhardwaj, A. 2006. Mechanisms of brain injury after global cerebral ischemia. Neurol. Clin. 24, 1-21.

10. Park, D., Joo, S. S., Lee, H. J., Choi, K. C., Kim, S. U. and Kim, Y. B. 2012. Microtubule-associated protein 2, an early blood marker of ischemic brain injury. Neurosci. Res. 90, 461-467.

11. McGeer, P. L., Schwab, C., Parent, A. and Doudet, D. 2003. Presence of reactive microglia in monkey substantianigra years after 1-methyl-4-phenyl-1, 2, 3, 6-tetrahydropyridine administration. Ann. Neurol. 54, 599-604.

12. Yang, H., Chopp, M., Weiland, B., Zhang, X., Tepley, N., Jiang, F. and Schallert, T. 2007. Sensorimotor deficits associated with brain tumor progression and tumor-induced brain plasticity mechanisms. Exp. Neurol. 207, 357-367.

13. Abraham, H. and Lazar, G. 2000. Early microglial reaction following mild forebrain ischemia induced by common carotid artery occlusion in rats. Brain Res. 862, 63-73.

14. Farkas, E., Luiten, P. G. and Bari, F. 2007. Permanent, bilateral common carotid artery occlusion in the rat: a model for chronic cerebral hypoperfusion-related neurodegenerative diseases. Brain Res. Rev. 54, 162-180.

15. Saxena, A. K., Majeed, A., Saad, S., Oothuman, P. and Mustafa, I. A. D. 2011. Lipid peroxidation in chronic cerebral hypoperfusion-induced neurodegeneration in rats. Inter. Med. J. Malaysia. 10, 3-6.

16. Farkas, E. and Luiten, P. G. 2001. Cerebral microvascular pathology in aging and Alzheimer's disease. Prog. Neurobiol. 64, 575-611.

17. Fujishima, M., Ogata, J., Sugi, T. and Omae, T. 1976. Mortality and cerebral metabolism after bilateral carotid artery ligation in normotensive and spontaneously hypertensive rats. J. Neurol. Neurosurg. Psychiatry. 39, 212217.

18. Al-Naggar, A.M.M, Atta, M.M.M, Ahmed. M.A. and Younis, A.S.M. 2016. Maximizing maize (Zea mays L.) crop yield via matching the appropriate genotype with the optimum plant density. J. A. L. Sci. Internat. 5, 1-18.

19. Derveaux, S. Vandesompele J. and Hellemans, J. 2009. How to do Successful Gene Expression Analysis Using Real-Time PCR. Methods.

20. Fleige, S. and Pfaffl, M. W. 2006. RNA integrity and the effect on the real-time qRT-PCR performance. Mol. Asp. Med. 27, 126-139.

21. Fleige, S., Walf, V., Huch, S., Prgomet, C., Sehm, J. and Pfaffl, M. W. 2006. Comparison of relative mRNA quantification models and the impact of RNA integrity in quantitative real-time RT-PCR. Biotechnol. Lett., 28, 16011613.

22. Bustin, S. A., Benes, V., Garson, J. A., Hellemans, J., Huggett, J., Kubista, M., Mueller, R., Nolan, T., Pfaffl W. M., Vandesompele, J. and Wittwer, W. C., 2009. The MIQE guidelines: minimum information for publication of quantitative real-time PCR experiments. Clin. Chem. 55, 611622. 
23. Lemos, M. L. d., Torre, A. V. d. 1., Petrov, D., Susana, B., Folch, J., Pallàs, M., Lazarowski, A., Beas-Zarate, C., Auladell, C. and Camins, A. 2013. Evaluation of hypoxia inducible factor expression in inflammatory and neurodegenerative brain models. Inter. J. Biochem. Cell Biol. 45, 1377-1388.

24. Zhou, T., Jiang, J., Zhang, M., Fu, Y., Yang, Z. and Jiang, L. 2013. Protective effect of mild hypothermia on oxygenglucose deprivation injury in rat hippocampal neurons after hypoxia. Mol. Med. Rep. 7, 1859-1864.
25. Annaházi, A., Mracsko, E.,Süle, Z., Karg, E., Penke, B., Bari, F. and Farkas, E. 2007. Pre-treatment and post-treatment with $\alpha$-tocopherol attenuates hippocampal neuronal damage in experimental cerebral hypoperfusion. Euro. J. Pharmacol. 571, 120-128.

26. Mani, V., Ramasamy, K., Ahmad, A., Parlec, M., Ali Shah, S.A. and Majeeda, A.B.A. 2013. Protective effects of total alkaloidal extract from Murraya Koenigii leaves on experimentally induced dementia. Food Chem. Toxicol. 50, 1036-1044. 